\title{
Measuring the Quality of Family-Professional Partnerships in Special Education Services
}

\section{JEAN ANN SUMMERS \\ University of Kansas \\ LESA HOFFMAN \\ JANET MARQUIS \\ ANN TURNBULL \\ DENISE POSTON \\ University of Kansas}

The Pennsylvania State University

\section{LOUISE LORD NELSON}

Noble of Indiana, Inc.

Aвstract: One difficulty in monitoring the quality of family-professional partnerships bas been the lack of a psychometrically acceptable and sufficiently general instrument with which to assess them. The current work describes the development of the Family-Professional Partnership Scale, which assesses parents' perceptions of the importance of and their satisfaction with family-professional partnerships. Indicators were constructed from qualitative research on families with children with and without disabilities, and the scale was refined across two field tests that included families with children with a wide range of ages and disability types and severity. Both the 18-item overall scale and the two 9-item subscales demonstrated excellent psychometric properties. The possible uses of this scale in future research and service delivery are discussed.

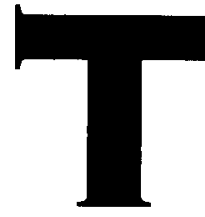

he importance of establishing positive partnerships between families and professionals in education has long been recognized (Summers, Gavin, Hall, \& Nelson, 2003). Parent involvement has been consistently related to students' cognitive development and academic achievement (Desimone, 1999; Halle, Kurtz-Costes, \& Mahoney, 1997; Simon, 2001; Trusty, 1999). In special education, the im- portance of positive partnerships is further reinforced in federal policy, which mandates parental involvement in educational decision making through the Individuals with Disabilities Education Act (IDEA; Turnbull \& Turnbull, 2001).

We use the term partnerships to encompass overlapping concepts described in the literature: collaboration, service integration, multidisciplinary teams, family or parent involvement, and, to some extent, family-centered services. We de- 
fine partnerships as mutually supportive interactions between families and professionals, focused on meeting the needs of children and families, and characterized by a sense of competence, commitment, equality, positive communication, respect, and trust (Blue-Banning, Summers, Frankland, Nelson, \& Beegle, 2004). Dunst and Paget (1991) listed six similar characteristics of partnerships: mutual contributions, shared responsibility, desire to work together, loyalty and trust, full disclosure, and agreement that parents are the final decision makers. The literature on parent involvement (e.g., Epstein \& Lee, 1995) describes family or parental responsibilities toward partnerships with professionals. Less well understood are the attitudes or behaviors of professionals, characterized as a "collaborative helping style" (Dunst, Trivette, \& Johanson, 1994, p. 198) needed to establish a positive partnership with families. That is the focus of the current work.

\section{U N D E STANDING PARTNERSHIPS}

Too often partnerships between families and professionals fall short of recommended practice. Partnerships are often a source of stress and concern for both parents and professionals (Summers et al., 2003). For example, parents describe problems communicating with their child's teacher (Blue-Banning et al., 2004), believe that professionals fail to understand and respect cultural differences (Kalyanpur \& Harry, 1999), perceive that getring appropriate and inclusive services for their child is a "forever and ongoing struggle" (Soodak \& Erwin, 2000, p. 36; Soodak et al., 2002), and feel blamed and judged for their child's problems (Osher \& Osher, 2002). Professionals report they are not adequately prepared to work with families, are not comfortable working with families, and/or are not supported by the school administration in their relationships with families (Brand, 1996; Katz \& Bauch, 1999; Tichenor, 1997).

Two important steps toward addressing these issues are (a) a better understanding of the skills and behaviors professionals need for a col- laborative helping style leading to partnerships with families (Dunst et al., 1994), and (b) the development of appropriate measures to evaluate these skills and behaviors. A better understanding of needed skills and behaviors would enhance training and practice, and appropriate measures would ensure effective evaluation of various intervention models provided within the context of a partnership.

\section{Professional BehaViors Related to PARTNERSHIPS}

Much of the available literature about partnership skills for professionals is qualitative and identifies relational or interpersonal factors, such as respect, commitment, and open communication (Dinnebeil \& Rule, 1994). Dinnebeil, Hale, and Rule (1996) identified personal characteristics and beliefs considered central to successful collaboration, such as friendliness, family-centered beliefs, integrity, commitment, and communication skills. Summers et al. (2001) found interpersonal factors such as sensitivity to parents, clarity, and respect were valued by parents and staff involved in collaborations between early intervention (Part $\mathrm{C}$ of

\section{Too often partnerships between families and professionals fall short of recom- mended practice.}

IDEA) programs and Early Head Start. A more complete description related to identification of interpersonal factors thought to contribute to service integration (a component of partnerships) may be found in Park and Turnbull (2003). The brief examples presented here illustrate that the identification of factors related to partnerships have occurred predominantly in qualitative studies.

\section{MEASUREMENT OF PROFESSIONAL PARTNERSHIP FACILITATION}

The current literature includes measures of family or parent satisfaction with services and measures of family-centered practice. Surveys of service sat- 
isfaction tend to measure the degree of parental satisfaction with the instrumental or outcome aspects of partnership (e.g., their perception of the helpfulness or value of the service), as well as satisfaction with relational aspects of their interactions with professionals. Measures of family-centered practice tend to measure the degree to which parents perceive the processes by which services have been delivered, that is, whether the professionals have been caring or $\mathrm{fa}$ cilitative of family empowerment. Taken together, the concepts of satisfaction with services and satisfaction with the intervention model or process (i.e., family-centered intervention) encompass the broader concept of partnership. The two concepts overlap but are not exactly the same; furthermore, they are not typically assessed with rigorously developed measures.

Satisfaction Measures. McNaughton (1994) noted that satisfaction measures tend to be developed specifically for a given study, with little attention to the psychometric evaluation or validation of the instrument. This trend has continued in the last decade. For example, the $\mathrm{Na}$ tional Early Intervention Longitudinal Study (NEILS) is following 3,338 children in early intervention. The first phase of the NEILS study included a parent interview with a number of broad objectives to investigate families' initial experiences with early intervention. Among these objectives was an assessment of parents' satisfaction with their involvement in decision making, feelings about the professionals working with their child, and whether early intervention professionals (a) respected their culture, (b) respected their opinions, or (c) made them feel optimistic and hopeful about their child's future (Bailey, Hebbeler, Scarborough, Spiker, \& Mallik, 2004). In a study of parent satisfaction by McWilliam, Lang, Vandiviere, Angell, Collins, and Underdown (1995), the authors constructed a measure with items that reflected the specific concerns of their state's Interagency Coordinating Council. Neither of these studies has reported information on the psychometric characteristics of their measures. We found one study with a psychometric evaluation of a measure of parent satisfaction. Lanners and Mombaerts (2000) reported the results of research to construct and evaluate a scale
Professionals report they are not adequately prepared to work with families, are not comfortable working with families, and/or are not supported by the school administration in their relationships with families.

to measure parent satisfaction with early intervention in 10 European countries. They developed a 57-item measure of parents' satisfaction with different aspects of early intervention services, which yielded a Cronbach's alpha for the scale at .95 and a Guttman split-half reliability coefficient of .89 .

Measures of Family-Centered Practice. A few studies have attempted to develop and evaluate measures that assess the degree to which families perceive services to be delivered in a family-centered way. Family-centered services are defined as respectful treatment of families, individualized and responsive practice, family choice, family-professional collaboration, and provision of supports to families as well as children in order to produce optimal child and family outcomes (Dunst, 2002). Measures of family-centered services include the Family Focused Intervention Scale (Mahoney, O'Sullivan, \& Dennebaum, 1990); the Brass Tacks, a self-rating of family-centered practices in early intervention (McWilliam, 1991); and the Family-Centered Program Rating Scale (Murphy, Lee, Turbiville, Turnbull, \& Summers, 1995). Finally, the Measure of Process of Care (MPOC; King, Rosenbaum, \& King, 1996) is also a measure of family-centered services in pediatric clinical settings primarily in Canada and the United Kingdom.

\section{PURPOSE OF THE CURRENT $S T \cup D Y$}

The measures reported in these studies are intended exclusively for use with families in early childhood services and/or within specific services such as clinical pediatric programs. Dunst (2002) noted that family-allied as opposed to family-centered program models are more often used in elementary and secondary education. This suggests that measures developed for early childhood pro- 
grams may not be appropriate for application in settings serving older children. In sum, no measure of family-professional partnerships for children and families with disabilities is currently available that (a) has been extensively evaluated psychometrically, (b) is applicable across the spectrum of ages of the child, (c) is not specific to a type of service or disability, and (d) efficiently encompasses a comprehensive conceptualization of the "collaborative helping style" (Dunst et al., 1994 , p. 198) required to support healthy family-professional partnerships. A measure that meets these criteria could enhance program and personnel evaluations, provide a basis for comparison across different types of service systems and age groups, identify specific skill or attitude needs for personnel development, and serve as a research tool to explore the relationships between partnerships and parent and child outcomes.

To investigate the components of partnership and develop a measure grounded in them, our research team engaged in a two-step process. The first step was a qualitative study to synthesize the perceptions of parents, service providers, and administrators about the specific behaviors and attitudes perceived as important for effective partnerships with professionals (Blue-Banning et al., 2004). This was a grounded-theory investigation (Strauss \& Corbin, 1998) involving analysis of the responses from focus group participants and individual interviews with non-English speaking families and their providers. The participants included families from high- and low-income groups; direct care service providers from agencies in health, education, and social services; and administrators. Our research team analyzed transcripts using the constant comparison method (Anfara, Brown, \& Mangione, 2002) of identifying, coding, and iteratively revising response categories to develop a series of indicators. These indicators were organized into six hypothesized domains of interpersonal partnership: professional skills, commitment, respect, trust, communication, and equality. Within each of these domains the indicators served to define the domain (e.g., listening as an indicator of communication, reliability as an indicator of trust). See Blue-Banning et al. for a detailed description.

In this article, the investigators report the second step of this research process, the develop- ment of a measure of family-professional partnership based on families' perceptions of the skills and attitudes professionals need for them to achieve a positive partnership with families. In Study 1 the instrument was created and refined, and in Study 2 the psychometric properties of the refined instrument were further examined using an additional sample.

\section{STUDY 1}

\section{METHOD}

Development of the Pilot Instrument. Ten items based on the indicators for each of the six hypothesized domains from the qualitative study were drafted for the Family-Professional Partnership Scale (Dillman, 2000). Items were written at a sixth-grade reading level, drafted to reflect the intent of the indicator, and worded to reflect the specific attitude sought. Respondents were asked to indicate how important each item was for their partnership with a professional serving their child using a 5-point scale, ranging from 1 (not at all important) to 5 (very important).

Pilot Testing. The pilot scale was administered to six individuals (parents and service providers) in order to obtain feedback on the relevance, clarity, possible offensiveness of any item, and the quality of instructions. The instructions were clarified to help respondents focus on one specific professional, and the partnership scale was translated into Spanish to enable the investigators to include Spanish-speaking respondents in the study.

Field Test Sampling and Procedures. Following the pilot test, a large-scale field test was conducted. In order to ensure representative geographic distribution, two states were selected (based on the research team's contacts) in each of four U.S. geographic regions: West (Arizona and California), Midwest (Illinois and Minnesota), Northeast (Pennsylvania and New York), and South (Louisiana and Texas). Within each state, school districts were selected to reflect urban, suburban, and rural distributions. Team members contacted school districts in the target areas; a uniform script was used to describe the study. Participating schools were offered a consultant 
payment for the staff member who would assist in the study and also were offered a selection of complimentary textbooks from University of Kansas faculty.

Twenty-five school districts agreed to participate in the study. The number of families needed from each state and school district was proportionate to the population of the state so that more families were sampled from larger states (e.g., Pennsylvania) and from urban districts (e.g., Los Angeles). These proportions were based on anticipated response rates and the number of recommended responses for exploratory factor analysis; the desired number of returns was 300 (i.e., 60 items $\times 5$ persons per item as recommended by Bentler, 1976). Contact staff members in participating districts were given a set of guidelines and procedures for sampling families who had children receiving special education services in their district. First, they were instructed to exclude children receiving speech services only. The team's rationale was that, because children receiving only speech services tend to have milder disabilities and compose a large proportion of the special education population, a random sample including these children might result in too few children with more complex needs. Second, the contact person in each school district was asked to alphabetize the names of the remaining children with disabilities who met the inclusion criteria, and third, to select every $n t h$ child based on the total number of children served and the desired number of returns. For example, when a sample of 50 children was needed out of a total of 600 children served in the district's special education program, every 12 th child was selected.

The contact person was sent sealed envelopes containing the invitation letters and response postcards and was asked to place mailing labels on the sealed envelopes based on their random selection. An appropriate number of Spanish versions were included depending on the reported proportion of Spanish-speaking parents in the district. If a family drawn in the random sampling included a Spanish-speaking parent, the contact person was asked to substitute the Spanish version of the packet being sent to that family. The final drafts of both versions were developed using scannable forms.
Families agreeing to participate sent the return postcards to the research team and were assigned an identification number and sent a survey packet within 1 week. Each packet included an instruction sheet, a survey booklet including demographic items, consent forms, a payment form $(\$ 20)$, and a postage-paid, preaddressed return envelope. The family member who interacted most often with the service system was asked to complete the partnership scale. A reminder postcard was sent to nonresponding families one month after the survey was sent.

In addition to school districts, representatives and administrators from the Parent to Parent and Grassroots Consortium networks also agreed to participate in the study. Parent to Parent organizations are programs that match parents who have recently learned of their child's disability with a "veteran" parent of a child with a disability (Santelli, Turnbull, Marquis, \& Lerner, 1997). The Parent to Parent organizations in this study were statewide associations from Arizona, North Carolina, South Carolina, and Vermont. Parent to Parent organizations were sent similar instructions and sealed invitation letters for selection of a sample from the parents on their mailing lists.

The Grassroots Consortium serves families of children with disabilities in traditionally underserved communities (Turnbull \& Turnbull, 2001). We solicited help from Grassroots programs in New York (serving African American and Latino families), California (serving Asian and Latino families), Minnesota (serving Latino families), Washington (serving Asian families), and Massachusetts (serving African American families) in order to include perspectives from culturally diverse groups who typically have low response rates for mail surveys (Dillman, 2000). Grassroots staff members invited families to a group meeting, where they facilitated completion of the scale (including translating and reading the items to families), collected the completed scales, and returned them to the researchers. Staff members were paid a small fee for their facilitation and were reimbursed for food, child care, transportation, and other meeting expenses; participating families received $\$ 20$.

Participants. A total of 1,899 families received invitations to participate. Of these, 508 
parents returned postcards indicating their willingness to participate in the study. In addition, 92 parents from Grassroots organizations completed the Family-Professional Partnership Scale. From both of these sources, a total of 310 parents returned surveys, although only 291 parents had sufficient data for use in the analyses. Individualand family-level demographic information for these 291 participants is displayed in Tables 1 and 2 , respectively. There were $251(87 \%)$ women and $38(13 \%)$ men, with 2 missing (1\%). There were $258(89 \%)$ biological or foster parents of a child with a disability, $11(4 \%)$ grandparents, 12 (4\%) respondents who considered themselves as "other," and 10 missing (3\%). Of the children with disabilities, there were 89 (31\%) girls and $196(67 \%)$ boys, with ages in years of $<5(25$, $9 \%), 5$ to $12(125,43 \%), 13$ to $18(93,32 \%)$, $19+(38,13 \%)$, and 10 were missing data $(3 \%)$. The reported disabilities of the children whose families were sampled included autism spectrum disorder; developmental delay; ADD/ADHD; mental retardation; emotional, learning, and physical disabilities; speech/language, vision, hearing, and health impairments; traumatic brain injuries; and mental illness. Of these disabilities, 49 children $(17 \%)$ were characterized by respondents as mild, $127(44 \%)$ as moderate, $67(23 \%)$ as severe, and $30(10 \%)$ as very severe; $9(3 \%)$ were reported as having an unknown severity level, and $9(3 \%)$ were missing data.

\section{RESULTS AND DISCUSSION}

Mean importance ratings for the 60 items on the 5-point response scale ranged from 3.89 to 4.89 $(M=4.67, S D=0.47)$. Two exploratory factor analyses with principal axis extraction were first conducted to investigate the structure of the importance ratings of the items and reduce the number of potential items. The first analysis extracted 11 "factors" with eigenvalues greater than one, many of which had only two or three items and were not conceptually interpretable. After rotation, only four factors emerged that included more than four items with loadings greater than .4. The second analysis specified six factors given that six domains were hypothesized, and a promax rotation was used to facilitate the production of an interpretable solution with correlated factors. The solution did not conform to the hy- pothesized structure, producing two clearly differentiated factors, each with at least eight items, two factors that had only a few items and that were closely related in content to the two factors with many items, and an additional two factors that did not have a clear interpretation because of the small number of items and their low factor loadings.

After eliminating items whose loadings on any factor were less than .4 , items that did not load strongly on just one factor, and items that were rated low on importance, additional exploratory factor analyses were conducted specifying two, three, or four factors. These solutions were examined both conceptually and statistically to determine the best factor structure for the scale. Conceptually, we sought dimensions that focused on meaningful constructs that were clearly distinct from each other, and for items that were unambiguous indicators of the underlying dimension. Statistically, we sought items that loaded strongly on only one factor and that comprised a scale with high internal consistency (reliability) as indicated by Cronbach's alpha. After examining the possible solutions as provided by the exploratory analysis, and determining that the reduced sets of items had acceptable reliability indexes (reported here), a two-factor solution was accepted. The item wordings were then refined to focus more on the concept embodied in the factor. Each resulting factor contained items related to both the behaviors and skills of the professional.

One factor, Child-Focused Relationships, included 11 items focused on the activities, attitudes, and services of the professional caring for the child with a disability (e.g., the importance of the professional being reliable and competent to meet the child's needs, being respectful of the child, and keeping the child's best interests in mind). The Cronbach's alpha for the Child-Focused Relationships items was .92. The second factor, Family-Focused Relationships, included 10 items related to respectful and supportive treatment of the family as a whole (e.g., polite communication, respect for the family's values); Cronbach's alpha was .91. 
TABLE 1

Participant Individual Demographics

Field Test 1

Field Test 2

Individual Variables

n $\%$ n $\%$

Ethnic Background

Hispanic

American Indian Non-Hispanic

Asian Non-Hispanic

$\begin{array}{llll}34 & 11.7 & 9 & 4.4\end{array}$

African American Non-Hispanic

White Non-Hispanic

Missing

$\begin{array}{rrrr}34 & 11.7 & 9 & 4.4 \\ 4 & 1.4 & 4 & 2.0 \\ 47 & 16.2 & 9 & 4.4 \\ 63 & 21.6 & 18 & 8.8 \\ 138 & 47.4 & 166 & 81.0 \\ 5 & 1.7 & 8 & 3.9\end{array}$

Marital Status

$\begin{array}{lrrrr}\text { Married } & 173 & 59.5 & 150 & 73.2 \\ \text { Widowed } & 14 & 4.8 & 1 & 0.5 \\ \text { Divorced } & 39 & 13.4 & 22 & 10.7 \\ \text { Separated } & 19 & 6.5 & 10 & 4.9 \\ \text { Never married } & 41 & 14.1 & 20 & 9.8 \\ \text { Missing } & 50 & 1.7 & 20 & 1.0\end{array}$

Employment Status

Employed full rime

$\begin{array}{llll}106 & 36.5 & 93 & 45.4\end{array}$

Employed part time

$\begin{array}{llll}60 & 20.6 & 30 & 14.6\end{array}$

Unemployed but looking

$\begin{array}{llll}15 & 5.2 & 4 & 2.0\end{array}$

Not employed (stay-at-home parent, retired, etc.)

$\begin{array}{llll}102 & 35.1 & 78 & 38.0\end{array}$

Missing

$\begin{array}{llll}8 & 2.7 & 0 & 0.0\end{array}$

Educational Background

No schooling completed

Formal schooling, no high school diploma or GED

High school graduate (diploma or GED)

Some college or post high school, but no degree

Associate degree (AA, AS, etc.)

Bachelor's degree (BA, BS, etc.)

Graduate degree

$\begin{array}{rrrr}6 & 2.1 & 6 & 2.9 \\ 46 & 15.8 & 15 & 7.3 \\ 73 & 25.1 & 36 & 17.6 \\ 80 & 27.5 & 47 & 22.9 \\ 33 & 11.3 & 19 & 9.3 \\ 24 & 8.2 & 56 & 27.3 \\ 19 & 6.5 & 25 & 12.2 \\ 10 & 3.4 & 0 & 0.0\end{array}$

Missing

2.9

7.3

9.3

27.3

0.0 
TABLE 2

Participant Family Demographics

Field Test $1 \quad$ Field Test 2

Family Variables

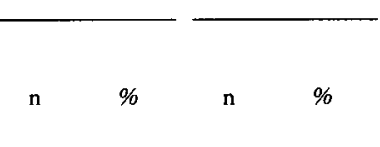

Community Type

Large city or metropolitan area $(>200,000)$
Small city $(50,000-200,000)$
Town $(2,500-50,000)$
Rural area or town $(<2,500)$
Missing

$\begin{array}{rrrr}132 & 45.4 & 49 & 25.4 \\ 41 & 14.1 & 32 & 16.6 \\ 70 & 24.1 & 83 & 43.0 \\ 31 & 10.7 & 26 & 13.5 \\ 17 & 5.8 & 3 & 1.6\end{array}$

Total Income

$<\$ 16,499 / \$ 13,999$
$\$ 16,500-\$ 24,999 / \$ 14,000-\$ 26,999$
$\$ 25,000-\$ 34,999 / \$ 27,000-\$ 34,999$
$\$ 35,000-\$ 49,999 / \$ 35,000-\$ 54,999$
$\$ 50,000-\$ 74,999 / \$ 55,000-\$ 75,000$
$>\$ 75,000$
Missing

$\begin{array}{rrrr}80 & 27.5 & 24 & 12.4 \\ 41 & 14.1 & 34 & 17.6 \\ 49 & 16.8 & 19 & 9.8 \\ 38 & 13.1 & 40 & 20.7 \\ 36 & 12.4 & 33 & 17.1 \\ 33 & 11.3 & 35 & 18.1 \\ 14 & 4.8 & 8 & 4.1\end{array}$

" The answer categories reflect those listed in Field Test 1/Field Test 2.

\section{STUDY 2}

Because the exploratory analyses in Study 1 substantially reduced the number of factors (and, consequently, items), we conducted a second field test in order to confirm the revised factor structure for the importance ratings of the Family-Professional Partnership Scale items and to establish the psychometric properties of the reduced scale. Given the overall high importance ratings for each of the items obtained in Study 1, the importance anchors were changed in Study 2 to encourage a wider range of response. The new anchors were: 1 (a little important), 3 (important, instead of somewhat important), and 5 (critically important). Study 2 also inquired as to the participants' satisfaction for each item, which also was rated on a 5-point ranging from 1 (very dissatisfied) to 3 (neither satisfied nor dissatisfied) to 5 (very satisfied).

\section{METHOD}

Sampling and Procedure. The sample for Study 2 was designed to provide an adequate sample size (at least 100 participants) to conduct the factor analyses of interest. We also attempted to achieve geographic diversity in our solicitation of participants. Participants were recruited by (a) presenting at national or state parent meetings about the scale and collecting responses from attendees; (b) presenting the scale and collecting responses at specially organized parent meetings; (c) recruiting help from state or local parent organizations, such as Parent to Parent groups or local groups affiliated with a state Parent Training and Information Center; and (d) recruiting help from community agencies wishing to conduct an evaluation of their programs.

For the national and state parent meetings, we collaborated with meeting organizers to get 
time on their agenda to make a brief presentation about the purposes of the partnership scale and to distribute it to the audience. We asked audience members to complete the scales and return them to us at the end of the presentation. The specially organized parent meetings were convened in collaboration with local agencies that invited parents to attend an evening meeting where a light supper was provided. We presented information about the purpose of the partnership scale, distributed the scales, and collected them in sealed envelopes at the end of the meeting. These participants received a $\$ 10$ participant payment in addition to reimbursement for their travel. In the parent organizations, we provided partnership scales to parent leaders, who then solicited respondents through their organizations in various ways, including convening group meetings and/or mailing surveys, as well as follow-up calls to encourage participants to complete and return the scales. Each parent leader was paid a small honorarium for time and postage expenses.

For the agency program evaluations, we worked with two agencies in Kansas and North Carolina interested in conducting an evaluation of parent satisfaction in their programs. We traveled to the Kansas agency (a local Head Start) and provided training to staff members who would be collecting the responses from families. The partnership scale data from the Head Start program were included in Study 2 only if the parents noted that their child had a disability. In the North Carolina agency, we provided written instructions and held phone conferences with local staff members responsible for distributing the partnership scales. The agency used various means to distribute and collect them (e.g., delivered by home visitors, distributed at parent meetings, or returned by mail). In summary, using all these strategies, we obtained respondents from the West (Washington), Midwest (Kansas, Michigan, Indiana and Indiana), Northeast (Pennsylvania), and South (North Carolina and Texas) regions.

Participant Description. Individual- and family-level demographic information for the 205 participants in Study 2 is displayed in Tables 1 and 2 , respectively. There were $168(82 \%)$ women and $34(17 \%)$ men, $3(2 \%)$ were missing. There were $184(96 \%)$ biological, foster, or adoptive parents, $5(3 \%)$ other relatives, and $2(1 \%)$ other nonrelatives. Of the children with disabilities, there were $61(32 \%)$ girls and $131(68 \%)$ boys, with ages in years of less than $5(83,43 \%)$, 5 to $12(71,37 \%), 13$ to $18(27,14 \%), 19$ or more, and missing responses $(11,6 \%)$. The reported disabilities of the children whose families were sampled included the same disabilities as were reported in Study 1. Of these disabilities, 29 (15\%) were characterized by the respondents as mild, $80(42 \%)$ as moderate, $48(25 \%)$ as severe, $17(9 \%)$ as very severe, $15(8 \%)$ as unknown, and 2 missing responses ( $1 \%)$.

\section{RESULTS AND DISCUSSION}

Three indices were used to evaluate the quality of fit in the confirmatory factor analysis models: the chi-square $(\chi 2)$, the Comparative Fit Index (CFI), and the Root Mean Square Error of Approximation (RMSEA). The $\chi 2$ value is an index of the extent to which the observed variances and covariances are accounted for by the system of equations specified in the model. Although a nonsignificant $\chi 2$ is desirable (i.e., no discrepancy between the model and the data), the $\chi 2$ values increase as a function of sample size, which means that in a large sample a trivial amount of misfit can lead to a significant $\chi 2$ value. Therefore, additional practical indices are often used to assess fit. The CFI is a measure of goodness-of-fit, where values above .90 or .95 indicate acceptable and excellent fit, respectively. The RMSEA is a measure of lack of fit, where values below .08 or .05 indicate acceptable and excellent fit, respectively (see Loehlin, 1998, for a more thorough treatment).

Importance Ratings. The importance ratings for the items were subjected to confirmatory factor analyses using Mplus version 3.0 (Muthén \& Muthén, 2004) with robust maximum likelihood estimation. Although the two-factor model developed in Study 1 had reasonably satisfactory fit statistics in this sample, conceptual and statistical examination of the scale revealed several possible changes that would improve the model fit. Two items that were originally assigned to the ChildFocused Relationships subscale were moved to the Family-Focused Relationships subscale because they appeared to be more conceptually related to the family subscale. The model fit statistics for the remaining 9 items in the Child-Focused Relation- 
ships subscale were: $\chi^{2}(27)=81, p<.001, \mathrm{CFI}=$ .89 , RMSEA $=.11$. After removing 3 items that were overly specific and redundant from the Family-Focused Relationships subscale, the model fit statistics for the remaining 9 items were: $\chi^{2}$ (27) $=47, p<.001, \mathrm{CFI}=.95$, RMSEA $=.07$. The resultant 18-item, two-factor model had fit statistics of: $\chi^{2}(134)=221, p<.001, \mathrm{CFI}=.91, \mathrm{RMSEA}$ $=.06$. Because a high correlation was obtained between the subscales $(r=.79)$, we also examined a one-factor model, with model fit statistics of $\chi^{2}$ $(135)=298, p<.001$, CFI $=.84$, RMSEA $=.09$, which was a significant decrease in fit as compared to the two-factor model, $\chi^{2}$ change $(1)=77, p<$ .001 . The Cronbach's alpha for the 18-item Partnership Scale for importance was .93 , with alphas of .90 and .88 for the 9-item Child- and FamilyFocused Relationships subscales, respectively. The mean importance ratings for the 18 items ranged from 4.10 to $4.85(M=4.50, S D=0.12)$ Tables 3 and 4 provide the item content, means, standard deviations, and item-toral correlations for the final Child-Focused and Family-Focused Relationships importance subscales, respectively. Table 5 provides the standardized solution for the two-factor model for importance ratings.

Satisfaction Ratings. The satisfaction ratings for the items were also subjected to confirmatory factor analyses to examine the extent to which the structure of the satisfaction responses was similar to that of the importance responses. The fit statistics for the single-factor models for the satisfaction ratings were: Child-Focused Relationships, $\chi 2(27)=47, p<.001$, CFI $=.97$, RMSEA $=.07$, Family-Focused Relationships, $\chi 2(27)=61$, $p<.001, \mathrm{CFI}=.94$, RMSEA $=.09$. The overall two-factor model had the following fit statistics: $\chi^{2}(134)=270, p<.001$, CFI $=.90$, RMSEA $=$ .08 . Although the correlation between the subscales was .94, the one-factor model, with fit statistics of $\chi^{2}(135)=292, p<.001, \mathrm{CFI}=.89$, RMSEA $=.09$, was a significant decrease in fit as compared to the two-factor model, $\chi 2$ change (1) $=22, p<.001$. The Cronbach's alpha for the 18-item Partnership Scale on satisfaction was .96, with alphas of .94 and .92 for the 9-item Childand Family-Focused Relationships subscales, respectively. The mean satisfaction ratings for the 18 items ranged from 3.47 to $4.41(M=4.04$, $S D=.13$ ). Tables 3 and 4 provide the item con- tent, means, standard deviations, and item-total correlations for the final Child-Focused and Family-Focused Relationships satisfaction subscales, respectively. Table 5 provides the standardized solution for the two-factor model for satisfaction ratings.

\section{DISCUSSION}

\section{SUMMARY OF FINDINGS}

The initial draft of the Family-Professional Partnership Scale was based on the results of a qualitative study that produced indicators representing attitudes and behaviors related to six domains: Professional Skills, Commitment, Respect, Trust, Communication, and Equality (Blue-Banning et al., 2004). In Study 1 exploratory analysis resulted in a reconfiguration of these six domains into two subscales: Child-Focused Relationships and Family-Focused Relationships. Confirmatory analyses on data from Study 2 confirmed the twofactor structure and examined further the psychometric properties of the Family-Professional Partnership Scale. These analyses indicated that each of the two subscales is sufficiently unidimensional and internally consistent. Also, as expected, the two subscales are strongly correlated with each other, indicating that they could be used as a single general measure of family-professional partnership.

The reduction in the number of domains in the final version of the Family-Professional Partnership Scale should not be surprising given the interrelatedness of the original constructs. For example, the focus group participants often described communication as a vehicle for demonstrating respect; professional commitment was viewed as a precursor to trust, and so on. Figure 1 depicts how items from the six original domains are included in the Child-Focused Relationships and Family-Focused Relationships subscales developed in the current studies. The Child-Focused Relationships subscale contains items from the original domains of Commitment and Professional Skills, as well as the items related to reliability and safety from the original Trust domain. The Family-Focused Relationships subscale contains items from the original domains of Communication and Equality, and items related to de- 
Importance

Your Child's Service Providers...

Satisfaction

\begin{tabular}{llllll}
\hline & & & & & \\
\hline
\end{tabular}

1. Help you gain skills or information to get what your child needs.

4.40

0.88

0.68

3.47

1.28

0.81

2. Have the skills to help your child succeed.

4.71

0.66

0.74

3.80

1.16

0.82

3. Provide services that meet the individual needs of your child.

$\begin{array}{llllll}4.73 & 0.63 & 0.73 & 3.67 & 1.26 & 0.85\end{array}$

4. Speak up for your child's best interests when working with other service providers.

5. Let you know about the good things your child does.

7. Build on your child's strengths.

8. Value your opinion about your child's needs.

9. Keep your child safe when your child is in their care.

pendability from the original Trust domain. The items from the original Respect domain are located within both factors, depending on the person to whom the professional is showing respect.

\section{LIMITATIONS OF THIS RESEARCH}

A concern of many researchers is the extent to which respondents are a representative sample of the population to which the work is being generalized. Given that potential participants can and often do refuse to participate, the resultant sample is only a subset of the initial random sample, and often no information is available about the nonparticipants. In Study 1, 43\% $(n=218)$ of the randomly selected families who indicated that they wished to participate returned surveys by 
TABLE 4

Partnership Family-Focused Relationship Subscale Item Descriptive Statistics

\begin{tabular}{|c|c|c|c|c|c|c|}
\hline \multirow{2}{*}{ Your Child's Service Providers... } & \multicolumn{3}{|c|}{ Importance } & \multicolumn{3}{|c|}{ Satisfaction } \\
\hline & M & $S D$ & $R_{\text {toral }}$ & M & SD & $\mathrm{R}_{\text {total }}$ \\
\hline 10. Are available when you need them. & 4.34 & 0.82 & 0.71 & 3.99 & 1.09 & 0.73 \\
\hline 11. Are honest, even when they have bad news. & 4.57 & 0.74 & 0.55 & 4.04 & 1.05 & 0.64 \\
\hline 12. Use words that you understand. & 4.10 & 1.00 & 0.75 & 4.36 & 0.84 & 0.71 \\
\hline 13. Protect your family's privacy. & 4.42 & 0.83 & 0.6 & 4.21 & 0.99 & 0.7 \\
\hline 14. Show respect for your family's values and beliefs. & 4.44 & 0.78 & 0.8 & 4.23 & 1.00 & 0.82 \\
\hline 15. Listen without judging your child or family. & 4.40 & 0.78 & 0.75 & 4.07 & 1.10 & 0.82 \\
\hline 16. Are people that I can depend on and trust. & 4.53 & 0.72 & 0.7 & 4.11 & 1.05 & 0.82 \\
\hline 17. Pay attention to what you have to say. & 4.55 & 0.72 & 0.76 & 4.13 & 1.06 & 0.83 \\
\hline 18. Are friendly. & 4.24 & 0.87 & 0.72 & 4.41 & 0.79 & 0.78 \\
\hline
\end{tabular}

mail. Although not initially randomly selected, the inclusion of the Grassroots Consortium participants $(n=92)$ who volunteered to complete the scale helped to increase the number of responses from typically underrepresented ethnic and socioeconomic groups, enabling an overall greater diversity in respondents. The participants in Study 2 were limited to parents who were present at meetings in which the scale was administered or who were being served by agencies conducting an evaluation, as previously described. The Study 2 sample was less socioeconomically diverse, comprised of a higher proportion of respondents with higher income levels and with young children as compared to Study 1 (see also Tables 1 and 2).

Given that the goal of the current work was to develop a general instrument that could be

$A$ concern of many researchers is the extent to which respondents are a representative sample of the population to which the work is being generalized. used with families of children of varying ages and disability types and severity, we constructed our samples accordingly. Future work should be conducted, however, to examine the extent to which the items on the Family-Professional Partnership Scale are applicable to a broad range of families from culturally and linguistically diverse backgrounds or to families of older children or adults with disabilities.

Another consideration is the extent to which the psychometric properties of the Family-Professional Partnership Scale might be compromised by lack of variability in the responses. Factor analyses are generally most appropriate for stable characteristics such as personality traits, attitudes, and values, which is the type of information sought in asking about the "importance" of each item with regard to quality partnerships. To enhance the broader utility of the scale, however, we purposefully eliminated items rated as relatively low in importance so that only indicators most relevant to high-quality partnerships were included in the final scale. The consequence is a restriction in the response range (e.g., in Study 2, the range for the item means on importance was 4.1 to 4.9 out of 5), which, in turn, limits the 


\begin{tabular}{|c|c|c|c|c|c|c|}
\hline \multirow[b]{2}{*}{ Item } & \multicolumn{3}{|c|}{ Importance } & \multicolumn{3}{|c|}{ Satisfaction } \\
\hline & Child Focused & Family Focused & $\begin{array}{c}\text { Error } \\
\text { Variance }\end{array}$ & Child Focused & Family Focused & $\begin{array}{c}\text { Error } \\
\text { Variance }\end{array}$ \\
\hline 1 & 0.61 & & 0.63 & 0.76 & & 0.42 \\
\hline 2 & 0.68 & & 0.54 & 0.76 & & 0.43 \\
\hline 3 & 0.72 & & 0.48 & 0.79 & & 0.38 \\
\hline 4 & 0.66 & & 0.57 & 0.77 & & 0.42 \\
\hline 5 & 0.71 & & 0.49 & 0.79 & & 0.38 \\
\hline 6 & 0.76 & & 0.42 & 0.84 & & 0.29 \\
\hline 7 & 0.85 & & 0.27 & 0.84 & & 0.29 \\
\hline 8 & 0.80 & & 0.35 & 0.86 & & 0.25 \\
\hline 9 & 0.81 & & 0.35 & 0.67 & & 0.55 \\
\hline 10 & & 0.73 & 0.47 & & 0.67 & 0.55 \\
\hline 11 & & 0.64 & 0.59 & & 0.67 & 0.55 \\
\hline 12 & & 0.59 & 0.65 & & 0.65 & 0.58 \\
\hline 13 & & 0.49 & 0.76 & & 0.65 & 0.57 \\
\hline 14 & & 0.81 & 0.35 & & 0.84 & 0.30 \\
\hline 15 & & 0.78 & 0.40 & & 0.86 & 0.27 \\
\hline 16 & & 0.77 & 0.41 & & 0.80 & 0.37 \\
\hline 17 & & 0.77 & 0.41 & & 0.85 & 0.27 \\
\hline 18 & & 0.63 & 0.61 & & 0.73 & 0.46 \\
\hline
\end{tabular}

strength of the observed correlations and the quality of model fit.

It should also be noted that, because satisfaction is a relatively temporary state, items rated on importance might not necessarily be rated similarly on satisfaction. Thus, a scale inquiring about importance of a set of items may have very good psychometric properties, but a scale asking about satisfaction with the same set of items may have worse (or very unstable) psychometric properties. The degree of fit observed in the confirmatory factor analysis models suggests that the level of satisfaction in these participants was relatively consistent across items, but this may not always be the case.
Finally, future evaluations are needed of the extent to which the Family-Professional Partnerships Scale demonstrates reliability and construct validity when used to evaluate the quality of partnerships. Several studies are currently being conducted to examine additional psychometric properties of the scale, including test-retest reliability and convergent validity. Preliminary results suggest that the Family-Professional Partnership Scale has acceptable test-retest reliability for both satisfaction and importance across a 3-month interval and is correlated with scores from related instruments, including the Family-Focused Intervention Scale (Mahoney et al., 1990) and the Disability-Related Support subscale of the Family 


\section{FIGURE 1}

Conceptual Framework of the Components of the Family-Professional Partnership Scale

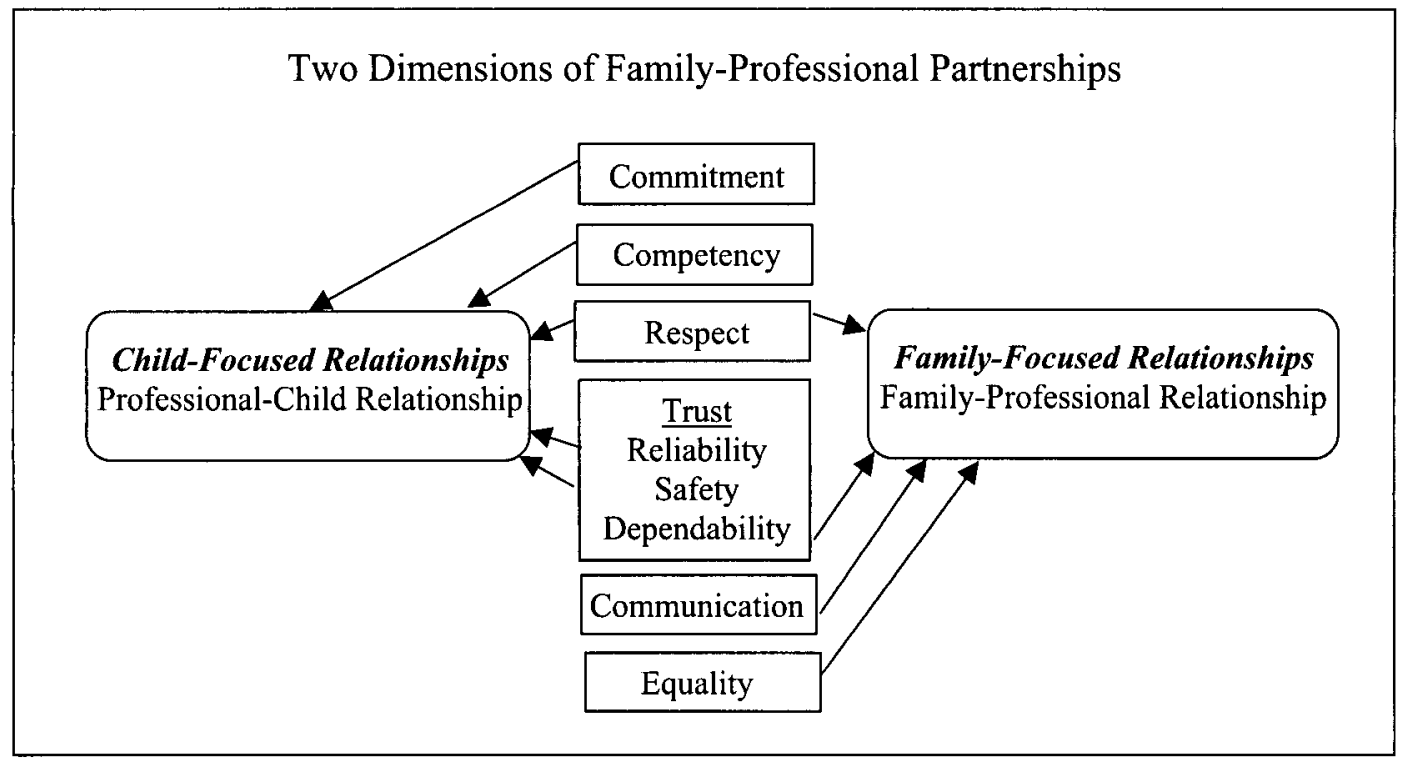

Quality of Life Scale (Park, et al., 2003; Summers et al., in press). The process of establishing the validity of the inferences drawn from the scale is well underway, but, of course, much remains to be done.

\section{IMPLICATIONS FOR FUTURE RESEARCH}

The primary outcome of this research is an 18item Family-Professional Partnership Scale with demonstrated acceptable internal reliability for both importance and satisfaction responses. Because this scale was developed and tested across a comprehensive range of families of children with disabilities, it has potential value for comparison studies across types of services, ages, and severity levels to assess the relative importance of and satisfaction with specific aspects of parent's partnerships with professionals.

The brevity of the Family-Professional Partnership Scale suggests it might have value in program evaluations to assess family satisfaction with services. This study suggests that there are some common attitudes and behaviors that parents may consider when asked about their satisfaction with any services. Studies of parent satisfaction with services have tended to focus on a particular issue, service category, or population that is being evaluated, such as satisfaction with inclusion (Hanline \& Halvorsen, 1989), satisfac- tion among Latino parents (Bailey, Skinner, Rodriguez, Gut, \& Correa, 1999), or satisfaction with early intervention programs (Mahoney et al., 1990). Paired with a checklist to determine which specific services the family and child are receiving, the Family-Professional Partnership Scale may be useful in pinpointing areas of strength and weakness across different programs, communities, or states.

Future work should be conducted, however, to examine the extent to which the items on the Family-Professional Partnership Scale are applicable to a broad range of families from culturally and linguistically diverse backgrounds or to families of older children or adults with disabilities.

\section{IMPLICATIONS FOR PRACTICE}

The Family-Professional Partnership Scale may serve as the basis for both preservice and in-service training on family-professional partnerships. The items could be used as points of discussion and dialogue between groups of professionals (or preprofessionals in training) and family members. 
Such a dialogue might include more in-depth discussion about why these items are important and what they mean, as well as collaborative discussions about facilitators or barriers to the ability of professionals and programs to display these attitudes and skills. These discussions, in turn, should lead to greater understanding and future plans for eliminating barriers to high-quality partnerships. The Family-Professional Partnership Scale could also be modified for use as an observational checklist for practicum supervisors or peer coaching teams. Students in practica could be evaluated on the degree to which they exhibit the attitudes and behaviors described in the scale. Similarly, peer coaches could use these indicators to help enhance partnerships with families or their colleagues.

Finally, the Family-Professional Partnership Scale could be useful for agency, schoolwide, or districtwide program evaluation or needs assessments by allowing the consideration of both importance of and satisfaction with each item. Graphical techniques could be used to identify irems to be prioritized for further discussion and action (e.g., items that are ranked relatively higher in importance but lower in satisfaction may need attention), whereas items that rank relatively high in both importance and satisfaction could be marked as program strengths.

\section{REF ERENCES}

Anfara, V. A., Jr., Brown, K. M., \& Mangione, T. L. (2002, October). Qualitative analysis on stage: Making the research process more public. Educational Researcher, 31(7), 28-38.

Bailey, D., Hebbeler, K., Scarborough, A., Spiker, D., \& Mallik, S. (2004). First experiences with early intervention: A national perspective. Pediatrics, 113, 887-896.

Bailey, D. B., Skinner, D., Rodriguez, P., Gut, D., \& Correa, V. (1999). Awareness, use, and satisfaction with services for Latino parents of young children with disabilities. Exceptional Children, 65, 367-381.

Bentler, P. M. (1976). Factor analysis. In P. M. Bentler, D. J. Lettieri, \& G. A. Austin (Eds.), Data analysis strategies and designs for substance abuse research (pp. 139-158). Rockville, MD: National Institute on Drug Abuse.

Blue-Banning, M., Summers, J. A., Frankland, C., Nelson, L. G., \& Beegle, G. (2004). Dimensions of family and professional partnerships: Constructive guidelines for collaboration. Exceptional Children, 70(2), 167-184. Brand, S. (1996). Making parent involvement a reality: Helping teachers develop partnerships with parents. Young Children, 51, 76-81.

Desimone, L. M. (1999). Linking parent involvement with student achievement: Do race and income matter? The Journal of Educational Research, 93(1), 11-30.

Dillman, D. (2000). Mail and Internet surveys: The tailored design method. New York: Wiley.

Dinnebeil, L. A., Hale, L. M., \& Rule, S. (1996). A qualitative analysis of parents' and service coordinators' descriptions of variables that influence collaborative relationships. Topics in Early Childhood Special Education, 19, 322-347.

Dinnebeil, L. A., \& Rule, S. (1994). Variables that influence collaboration between parents and service coordinators. Journal of Early Intervention, 18, 349-361.

Dunst, C. J. (2002). Family-centered practices: Birth through high school. The Journal of Special Education, 36(3), 139-147.

Dunst, C. J., \& Paget, K. D. (1991). Parent-professional partnerships and family empowerment. In $\mathrm{M}$. Fine (Ed.), Collaborative involvement with parents of exceptional children (pp. 25-44). Brandon, VT: Clinical Psychology Publishing Company.

Dunst, C. J., Trivette, C. M., \& Johanson, C. (1994). Parent-professional collaboration and partnerships. In C. J. Dunst, C. M. Trivette, \& A. G. Deal (Eds.), Supporting of strengthening families, Vol. 1: Methods, strategies and practices (pp. 197-211). Cambridge, MA: Brookline Books.

Epstein, J., \& Lee, S. (1995). National patterns of school and family connections. In B. Ryan, G. Adams, T. Gullota, R. Weissberg, \& R. Hampton (Eds.), The family-school connection: Theory, research and practice (pp. 108-154). Thousand Oaks, CA: Sage.

Halle, T., Kurtz-Costes, B., \& Mahoney, J. (1997). Family influences on school achievement in low-income, African American children. Journal of Educational Psychology, 89, 527-537.

Hanline, M. F., \& Halvorsen, A. (1989). Parent perceptions of the integration transition process: Overcoming artificial barriers. Exceptional Children, 55, 487-492.

Kalyanpur, M., \& Harry, B. (1999). Culture in special education: Building reciprocal family-professional relationships. Baltimore, MD: Paul H. Brookes.

Katz, L., \& Bauch, J. (1999). The Peabody family involvement initiative: Preparing preservice teachers for 
family/school collaboration. The School Community Journal, 9, 49-69.

King, S. M., Rosenbaum, P. L., \& King, G. A. (1996). Parents' perceptions of caregiving: Development and validation of a measure of processes. Developmental Medicine and Child Neurology, 38, 757-772.

Lanners, R., \& Mombaerts, D. (2000). Evaluation of parents' satisfaction with early intervention services within and among European countries: Construction and application of a new parent satisfaction scale. Infants \& Young Children, 12(3), 61-70.

Loehlin, J. C. (1998). Latent variable models (3rd ed.). Mahwah, NJ: Lawrence Erlbaum Associates.

Mahoney, G., O’Sullivan, P., \& Dennebaum, J. (1990). Maternal perceptions of early intervention services: $A$ scale for assessing family focused intervention. Topics in Early Childhood Special Education, 10, 1-15.

McNaughton, D. (1994). Measuring parent satisfaction with early childhood intervention programs: Current practice, problems, and future perspectives. Topics in Early Childhood Special Education, 14, 26-48.

McWilliam, P. J. (1991). Brass Tacks: A self-rating of family-centered practices in early intervention. Chapel Hill, NC: Frank Porter Graham Child Development Center, The University of North Carolina at Chapel Hill.

McWilliam, R. A., Lang, L., Vandiviere, P., Angell, R., Collins, L., \& Underdown. G. (1995). Satisfaction and struggles: Family perceptions of early intervention services. Journal of Early Intervention, 19(1), 43-60.

Murphy, D. L., Lee, I. M., Turbiville, V., Turnbull, A. P., \& Summers, J. A. (1995). The family-centered program rating scale: An instrument for program evaluation and change. Journal of Early Intervention, 19, 24-42.

Muthén, B. O., \& Muthén, L. K. (2004). Mplus user's guide (3rd Ed.). Los Angeles, CA: Muthén \& Muthén.

Osher, T. W., \& Osher, D. M. (2002). The paradigm shift to true collaboration with families. Journal of Child and Family Studies, 11, 47-60.

Park, J., Marquis, J., Hoffman, L., Turnbull, A., Poston, D., Mannan, H., Wang, M., \& Nelson, L. (2003). Assessing family quality of life as the service outcome. Journal of Intellectual Disability Research, 47(5), 367384.

Park, J., \& Turnbull, A. P. (2003). Service integration in early intervention: Determining interpersonal and structural factors for its success. Infants \& Young Children, $16(1), 48-58$.

Santelli, B., Turnbull, A. P., Marquis, J. G., \& Lerner, E. (1997). Parent to parent programs: A resource for parents and professionals. Journal of Early Intervention, 2I(1), 73-83.

Simon, B. S. (2001). Family involvement in high school: Predictors and effects. NASSP Bulletin, 85, 819.

Soodak, L., \& Erwin, E. (2000). Valued member or tolerated participant: Parents' experiences in inclusive early childhood settings. Journal of the Association for Persons With Severe Handicaps, 25, 29-41.

Soodak, L. C., Erwin, E. J., Winton, P., Brotherson, M. J., Turnbull, A. P., Hanson, M. J., et al. (2002). Implementing inclusive early childhood education: A call for professional empowerment. Topics in Early Childhood Special Education, 22(2), 91-102.

Strauss, A., \& Corbin, J. (1998). Basics of qualitative research: Techniques and procedures for developing grounded theory. Thousand Oaks, CA: Sage.

Summers, J. A., Gavin, K., Hall, T., \& Nelson, J. (2003). Family and school partnerships: Building bridges in general and special education. In F. E. Obiakor, C. A. Utley, \& A. F. Rotatori (Eds.), Advances in special education: Psychology of effective education for learners with exceptionalities (pp. 417-445). Stamford, CT: JAI Press.

Summers, J. A., Poston, D. J., Turnbull, A. P., Marquis, J., Hoffman, L., Mannan, H., et al. (in press). Conceptualizing and measuring family quality of life. Journal of International Disability Research.

Summers, J. A., Steeples, T., Peterson, C., Naig, L., McBride, S., Wall, S., Liebow, H., Swanson, M., \& Stowitschek, J. (2001). Policy and management supports for effective service integration in Early Head Start and Part C programs. Topics in Early Childhood Special Education, 21, 16-30.

Tichenor, M. (1997). Teacher education and parent involvement: Reflections from preservice teachers. Journal of Instructional Psychology, 24, 233-240.

Trusty, J. (1999). Effects of eighth-grade parental involvement on late adolescents' educational expectations. Journal of Research \& Development in Education, 32(4), 224-233.

Turnbull, A. P., \& Turnbull, H. R. (2001). Families, professionals, and exceptionality: $A$ special partnership. Columbus, $\mathrm{OH}$ : Merrill.

\section{ABOUT THE AUTHORS}

JeAn ANN summers (CEC MO Federation) Research Associate Professor, Beach Center on Disability, University of Kansas, Lawrence. LESA 
Copyright of Exceptional Children is the property of Council for Exceptional Children. The copyright in an individual article may be maintained by the author in certain cases. Content may not be copied or emailed to multiple sites or posted to a listserv without the copyright holder's express written permission. However, users may print, download, or email articles for individual use. 